\title{
Influence and Countermeasures Research on Ideological and Political Education of College Students with WeChat
}

\author{
Yao Li \\ Huanghe Science \& Technology College, Zhengzhou, China \\ wxkbbg@163.com
} Keywords: WeChat; College students; Ideological and political education; Influence;
Countermeasures

\begin{abstract}
With the rapid development of technology, WeChat is the hottest social information platform and has become the most popular communication mode. WeChat offers college students new space of the exchange information, interactive learning and emotional catharsis, while is has a significant impact on the ideological and personality formation. Therefore, by studying the impact of ideological and political education of college students with WeChat, then proposed the countermeasures to enhance the ideological and political education of college students with WeChat.
\end{abstract}

\section{微信对大学生思想政治教育的影响和对策研究}

\author{
李耀 \\ 黄河科技学院, 郑州 中国
}

摘要: 随着科技的飞速发展, 微信作为时下最热门的社交信息平台, 已经成为现代社会最青 睐的网络交流方式。微信为大学生提供了信息交流、互动学习、宣泄情感的新域所, 同时对 大学生思想、人格形成产生了重要影响。因此, 要研究微信对大学生思想政治教育的影响, 提出利用微信增强大学生的思想政治教育工作的对策。

关键词：微信; 大学生; 思想政治教育; 影响; 对策

\section{1. 前言}

随着信息技术的发展和经济全球化，中国改革开放不断深化，中国已经由过去的信息落后时 代转化为信息高速化时代。尤其是网路技术的飞速发展，使人们的生活发生了翻天覆地的变 化, 微信就是近几年发展最快的一种信息化网络技术, 已经广泛深入人心，普及到千家万户， 在工作学习中占据主导地位。

对于现如今的大学生而言, 微信已然成为一种新的生活方式。对于高校思想政治教育来说, 微信是一把 “双刃剑”, 它以极强的渗透力和吸引力给当前大学生思想政治教育带来了新的机 遇和挑战。新时期开展大学生思想政治教育工作，大学生思想政治教育工作者应充分运用微 信，不断加强、改进、拓展现有的思想政治教育工作，创新工作方式、方法。

\section{2. 微信对大学生思想政治教育的影响}

现如今，由于信息化和网络化的高速发展，微信以迅雷不及掩耳之势，已经发展成为当代大 学生使用的新兴的主流社交媒体。对于高校思想政治教育工作而言, 微信既有好的作用, 又 有坏的影响, 既带来了机遇, 也伴随着挑战。

\section{1. 微信给大学生思想政治教育带来的新机遇}

（1）微信为大学生之间、师生之间提供了自由沟通的平台，增强了实效性。

当今社会, 随着获取信息渠道和内容的不断丰富, 单纯的课堂教学已经不能完全激发学生的 
学习兴趣, 预期的教育效果也难以达到, 因此, 高校传统的思想政治教育正面临着严峻的挑 战。微信, 作为公共的手机和网络平台, 大大降低了使用者的准入门槛, 使通信简单易用, 更加方便、快捷, 为大学生提供了良好的获取信息资源、表达观点、交流思想的平台。大学 生可以通过微信来表达自己的观点态度以及所思所想, 思想政治工作者也可以通过微信中传 达的这些讯息来了解大学生的生活现状、心理变化, 从而进行及时有效的疏导与沟通, 建立 心理预警机制, 将可能出现的问题扼杀在萌芽中, 促进学生积极健康成长。大学生思想政治 教育无须受场所和环境的影响, 借助微信, 挖掘大量、丰富的信息资源, 也可以通过微信主 动地、快速地传播正确的思想观念、理论与政策。无论是教育方法与教育手段, 还是信息获 取与传播, 都将取得突破性的改善, 从而为大学生思想政治教育提供了全新的、广阔的理论 与实践平台。

（2）微信丰富了大学生思想政治教育的内容，拓展了大学生思想政治教育的途径。 微信使大学生的生活变得更加的丰富充实, 处于青春期的大学生, 思想活跃, 精力充沛, 兴 趣广泛, 人际交往的需求极为强烈。他们喜欢将看到的精彩内容、生活感想、优美图片等信 息分享到朋友圈, 把微信作为自己与外界交往的首选媒介。思想源于生活, 深入地了解大学 生的思想, 就要走进大学生的生活。高校思想政治教育工作者可通过微信平台实时了解学生 的思想动态和需求, 实现对大学生思想和价值观的正确引导。

与传统媒体相比, 微信这类新媒体承载了巨大的信息量, 拥有巨大的信息源, 信息更新的速 度更快。通过微信师生可以自由地进行思想交流，迅速了解到国内外正在发生的政治、经济、 文化、生活等各方面的信息, 进一步充实和丰富大学生思想政治教育的内容。微信把过去那 些静止的、抽象的知识, 转化为动态的、具体的画面, 让大学生从视觉、听觉上得到综合感 官的刺激, 无疑为思想政治教育拓宽了新的途径。

(3) 微信促进了大学生思想政治教育方式、手段的转变。

利用微信开展大学生思想政治教育, 改变过去思想政治教育枯燥乏味的说教形式, 采取现代 化、先进化的教育方式, 加强师生间的沟通, 把思想政治教育内容渗透到大学生的生活中, 实现了教育者和受教育者之间的双向互动, 大大激发了受教育者的能动性, 促进了思想政治 教育方式、手段的转变，起到良好的思想政治教育效果。

（4）微信促进了大学生思想政治教育社会化。

当前大学生思想政治教育工作的发展瓶颈就是没有实现家庭、社会与学校之间的互动, 没有 将社会因素纳入到大学生思想政治教育体系中, 而微信的出现则为家庭、社会、学校与学生 之间的互动交流提供了良好的发展平台, 通过微信平台学生可以将平时不愿意说的话, 在微 信中发表, 而学校、家庭以及社会可以根据学生的问题进行互动与交流, 进而帮助学生解决 思想政治意识问题。

2.2. 微信给大学生思想政治教育带来的新挑战

（1）微信中的信息较复杂, 导致大学生的世界观、人生观和价值观模糊。

微信的引入和兴起, 颠覆了传统的信息传播方式。在以微信为载体构建的网络社会中, 每个 人都是信息的制造者和传播者，信息鱼龙混杂，缺乏正确的指导和把关，在一定程度上会影 响大学生的世界观、人生观和价值观, 使当前大学生思想教育工作面临着极为复杂严峻的挑 战。

微信上的信息庞杂多样，既有积极、进步的信息，也有消极、落后的信息。所有这些信息混 杂在一起, 往往会使人无所适从, 特别是对大学生而言, 容易受到各种不良信息、不道德行 为甚至是违法行为的干扰。同时, 宽松自由的环境给了人们不受约束的空间, 使其自由发表 各种言论, 其中不乏有一些不负责任的言语和负面的情绪, 这容易影响到大学生的思想、观 念, 模糊大学生的世界观、人生观和价值观, 增加思想政治教育工作的难度。

（2）微信削弱了大学生思想政治教育传统方法的效果。

在传统的思想政治教育过程中, 思想政治教育者往往专注于灌输。教育者根据教育目的, 有 意识、有针对性地对大学生集中地、持续地传播含有特定内容的信息, 通过课堂教育等一些 
带有很大强制性的方法, 传播主流思想, 进一步转变大学生的思想观念与行为。而微信的出 现, 使大学生可以在毫无约束的氛围中直接面对各种信息的诱惑, 大学生对所接触的信息已 经逐步脱离了教师与家长等的权威控制。多元化的价值观在微信中也得到了淋漓尽致的体现, 这些价值观在主流舆论之外不断扩张、并且发挥作用, 对主流价值观造成了严峻的挑战。随 着微信的快速发展, 传统的高校思想政治教育方法滞后等弊端逐渐显示出来, 传统的教育模 式如果不能随着时代的发展而发展, 将不能很好地了解大学生的思想动向, 更无法对他们开 展有效的思想政治教育。

（3）微信弱化了大学生思想政治教育主体的地位。

思想政治教育主体是思想政治教育的承担者、发动者和实施者, 在思想政治教育中起着主导 性和决定性的作用。在新媒体时代, 由于微信的广泛使用, 大学生渐渐强调自我的主张。在 微信中, 人人皆 “主体”，使作为高校思想政治教育组织、发动、实施者的教育工作者在很大 程度上丧失了信息优势, 由此带来教育过程中思想政治教师主导者的角色被弱化, 思想政治 教育的主体由整个教育的中心人物变为平等的参与者。这就增加了大学生正确价值观引导的 难度, 与此同时也打破了传统模式下的思想政治教育主体的权威地位, 冲击着大学生思想政 治教育工作者的主导地位。

（4）微信交流的虚拟性, 影响大学生实际交际能力的培养。

微信具有明显的虚拟性, 任何人可以通过匿名或者化名等进行不规范的网络交流, 并且可以 随意发表一些不正确的言论, 久而久之使得大学生出现了人际信任危机, 大学生长时间在微 信中进行交流, 会导致他们的实际交际能力越来越差, 并且会出现一定的心理问题, 比如他 们对于任何人的语言都会产生怀疑, 结果影响自己与他人建立良好的人际关系的基础。

\section{3. 利用微信加强大学生思想政治教育的对策}

（1）树立正确的微信观念, 制定和完善相关的法律法规.

微信作为当代一种新兴的网络媒介, 被人们所接受。作为高校思想政治教育工作者, 要引导 学生树立正确的微信观念; 要加强对微信的引导和管理, 防范西方文化意识渗透, 弘扬民族 精神主旋律; 要重视微信在思想政治教育中的功能作用, 多管齐下, 找准结合点, 坚持用健 康、积极、高尚的主流文化引导大学生的思想观念、价值取向和行为方式, 巩固意识形态安 全, 引导大学生完善人性, 塑造理想人格, 升华人生境界。

（2）利用微信构筑思想政治教育工作网络平台，强化师资队建设。

当前大学生使用微信看新闻、联系朋友和家人, 已成为日常生活的一部分。高校的思想政治 教育工作者应敏锐地看到这一现象, 积极开辟微信教育阵地, 打造校园学生微信群吧、微信 论坛等新媒体平台, 建构多层次、全方位的校园微信网络, 随时随地了解学生动态, 深入开 展工作, 充分发挥微信教育的功能。大学生思想政治教育工作者作为大学生思想政治教育工 作的主体, 应当与时俱进, 充分掌握现代大众传媒的相关知识, 不断提高运用微信这类现代 媒体的能力, 将思想政治教育与微信结合起来, 改进和加强大学生思想政治教育的效果, 更 好地为大学生思想政治教育服务。

（3）鼓励大学生展示自我, 实现梦想。

高校要积极探索和创新, 从大学生自我意识发展的规律入手鼓励大学生展示自我, 尊重学生 的思想和感情, 正面看待大学生的学习需求和微信诉求。辅导员、教师应对学生进行耐心细 致的引导, 引导学生正确使用微信, 通过微信展示生活正能量, 关注每个在校大学生, 调动 各种资源创造条件, 帮助他们激发梦想, 展示梦想, 形成主动追寻梦想并为之努力的氛围。

（4）教育大学生培养良好的阅读习惯。

基于微信等的新媒体带来了阅读变革和新媒体发展的不可抗拒性。必须正视这些新媒体带来 的机遇和挑战。数字阅读不再单纯以文字为载体, 更包含了图片、视频、音频等符号, 有很 强的吸引力。传播内容主要包含幽默笑话、娱乐资讯、文学作品、学习资料、时事新闻、杂 谈等。要积极引导学生通过阅读, 满足学习和生活需求, 拓展个人的知识储备、丰富精神世 
界、开发个人潜力, 并积极参与校园、公益等活动。

（5）建立微信群，畅通沟通渠道。

面对大学生 “无人不微” 的现实, 高校思想政治教育工作者应建立班级、社团微信群, 添加 学生为好友, 经常互动交流, 利用朋友圈分享有价值、有吸引力的思想政治教育材料, 密切 关注和研究微信发展新动向, 少封堵、多疏导, 少灌输、多交流, 让微信成为掌握大学生思 想动态的 “心电图”、沟通交流情感的 “贴心桥”、反馈意见建议的 “直通车”，解决各类现实 需求与问题。

（6）建立公众号，抢占思想政治教育制高点。

应改进教育方式方法, 利用学校、学院、社团等微信公众号平台开展思想政治教育, 提升思 想政治教育工作者的微素养, 强化教育者的主导作用, 使教育者了解微信特性、功能及其传 播优势, 全面掌握并驾驭微信。思想政治教育课教师可利用微信的即时性、互动性特点, 将 微信与传统教学结合, 开展多样化的教学。建立学校、班级、支部等公众号, 辅导员、班主 任、教师通过发布思想政治理论、专题知识、活动动态等, 与大学生进行良性互动, 有针对 性地进行思想引导，避免可能出现的思想和人生价值观偏航和误差。

(7) 建立危机干预机制, 提高大学生综合素养。

建立微信侵权侵害干预机制, 及时提供警示的制度、网络、方法等预警措施, 超前反馈、及 时布置、防风险于未然, 打信息安全主动仗。定期开展危机和案例警示教育, 帮助大学生树 立正确的媒体观念, 提高其辨别信息真伪的能力, 培养其善用微信资源的好习惯。教育学生 懂得隐私设置; 交友时要保持警惕, 不要轻易见面; 如果涉及钱财, 要三思而后行; 发现问 题及时向教师和警方求助。同时充分发挥與论引导力，利用微信发布权威信息，对校园突发 事件或虚假传言等及时澄清, 消除学生群体可能的疑惑和不满, 引导其做自觉遵纪守法的典 范。

\section{参考文献}

[1] 徐瑞娴.从公益性草根民间组织看思想政治教育的完善J].思想政治研究, 2012 (4) : 23-25

[2] 祁承勇.大学生网络思政教育工作的现状与对策研究[J]. 党史博采(理论), 2015 (05):32-34

[3] 董颖,李鹰.论如何有效发挥专业教师在大学生思政教育工作中的作用 $[\mathrm{J}]$. 亚太教育, 2015 (21):65-67

[4] 张淳.信息时代大学生思政教育工作优化的研究[J]. 时代教育.2014（11）:42-44

[5] 罗祥莉.试论当前高校学生思政教育工作的意义及做法 [J]. 黔南民族医专学报, 2013 (01):36-37

[6] 丛利红.微信在大学生思想政治教育中的应用探析.西部素质教育，2016（02）：21-23

\section{References}

[1]. Ruixian Xu. The improvement of Ideological and political education based on the public welfare grass-roots organizations [J]. The study of Ideology and Politics, 2012 (4): 23-25

[2]. Chengyong Qi. College students' Network Ideological and political education of the status quo and countermeasure research of [J]. The history of gambling (Theory) (05): 32-34, 2015

[3]. Ying Dong, Ying Li. How to effectively develop the function of the professional teachers in the ideological and political education of college students [J]. Asia Pacific Education, 2015 (21): 65-67

[4]. Chun Zhang. Study on work optimization of college students' Ideological and political education in information age [J]. Education Times, 2014 (11): 42-44 
[5]. Xiangli Luo. On current university student thought political education work the significance and practice [J]. Journal of Qiannan Medical College, 2013 (01): 36-37

[6]. Lihong Cong. Application of WeChat in the ideological and political education. Western Quality Education, 2016 (02): 21-23 